\title{
The Place of Translated ChILDREN's Literature IN THE GREEK BOOK MARKET AND FACTORS THAT INFLUENCE ITS SELECTION AND TRANSFER
}

\author{
O LUGAR DA LITERATURA INFANTIL TRADUZIDA NO MERCADO LIVREIRO \\ GREGO E OS FATORES QUE INFLUENCIAM SUA SELEÇÃO E TRANSFERÊNCIA
}

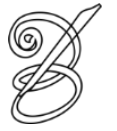 \\ Petros PANAOU* \\ University of Georgia, USA \\ Tasoula TSILIMENI** \\ University of Thessaly, Greece
}

\begin{abstract}
This paper looks at how the translated children's literature segment has been evolving in the Greek book market, while also exploring factors that play a central role in its selection and transfer from other countries to Greece. For these purposes, it utilizes published quantitative data, while also developing a qualitative analysis of five interviews, conducted with three Greek translators and two executives from prominent publishing houses in Greece.

Keywords: Children's literature. Translated children's books. Selection and transfer. Greek book market. Interviews.

Resumo: Este artigo observa como o segmento de literatura infantil traduzida tem evoluído no mercado livreiro grego, explorando os fatores que exercem um papel central em sua seleção e transferência a partir de outros países para a Grécia. Para estes fins, empregam-se dados quantitativos já publicados, ao mesmo tempo em que se desenvolve uma análise qualitativa de cinco entrevistas, conduzidas com três tradutores gregos e dois executivos de importantes editoras na Grécia.
\end{abstract}

Palavras-chave: Literatura infantil. Livros infantis traduzidos. Seleção e transferência. Mercado livreiro grego. Entrevistas.

RECEBIDO EM: 23 de fevereiro de 2019

ACEITO EM: 04 de maio de 2019

PUBLICADO EM: julho 2019 


\section{An introduction to translated children's literature in Greece}

his paper aims to explore the place of translated children's literature in Greece and
identify the factors that influence its selection and transfer from other countries to
Greece. Emer O'Sullivan observes that 'Children's literature has transcended linguistic and cultural borders since books and magazines specifically intended for young readers were first produced on a significant scale in eighteenth-century Europe" (1). Translation and transfer are the vehicles on which stories have been travelling across linguistic and cultural borders, at the same instance crossing spatial borders between nations as well as time boundaries from one era to another. Translation and transfer of stories, mainly from the west, has been a central part of Greek children's literature ever since its inception.

Ntelopoulos (38) reports that over the course of the $19^{\text {th }}$ century, 293 children's books by 114 different authors were translated into Greek and published in 510 different editions. These numbers are quite impressive when compared to the significantly narrower production of original Greek texts for children during the same time period: 204 titles; 98 Greek authors; 330 editions. The majority of translated texts came from France or via France (for instance 166 French versions of stories from Italy). Ntenisi observes that the majority of books for adults was also being imported from France during that time period. In general, nine out of ten $19^{\text {th }}$ century translations were imported in Greece from France (21). Several reasons are provided by scholars to explain this tendency. To begin with, Greeks - and thus Greek translators-were better skilled in French, as it was the main foreign language they were being taught. Secondly, a big number of texts from other countries were consistently being translated and published in French, so all these texts were also available for French-to-Greek translation. Thirdly, people living in Greece at the time had negative dispositions towards England, because of that country's hostile politics towards Greek issues of national concern (Ntelopoulos; Ntenisi).

Diachronically, translations have been having a significant effect on Greek authors' writing themes and styles (Anagnostopoulos) and European influences on Greek culture can be traced in the children's texts imported from other European countries to Greece (Ntelopoulos). According to Dimitrios Politis, there have been formative modern and postmodern European influences on contemporary Greek children's literature; by the French author Michel Tournier and the Italian Gianni Rodari, for instance (54).

Considering the centrality of translated texts for children and youth in Greece, the rarity of relevant comparative and translation studies is quite surprising. It is indicative that the authors of this paper had considerable difficulty in locating information about the evolution of 
children's and Young Adult (YA) translations in $20^{\text {th }}$ century Greece. We were, however, able to infer that translated texts for children continued to outnumber texts written by Greek authors up until the 1970s. During the 70s the situation was reversed, with locally produced children's titles beginning to outnumber translated ones; nevertheless, translations continued to be imported in significant numbers (Anagnostopoulos 27). The collapse of the dictatorship in 1974 and the transition to democracy brought about liberal educational theories and reforms and cultural convergence with Europe. These changes inspired and motivated Greek authors to write for children prolifically, focusing on child perspectives and addressing their child readers as important, active, and critical members of society (Katsiki-Givalou; Panaou).

The 1970s was also the decade during which translations from English started to outnumber those from French (Anagnostopoulos 14).

This paper, part of which was presented at the Child and the Book Conference in Athens, aims to develop the discussion around the current state of children's literature translation in Greece, contributing to the study of this important but thus far neglected field. We view our work as a "contact and transfer study" as described by O'Sullivan, in the sense that it is concerned with the cultural exchange between literatures from different countries, languages, and cultures. We look at how the translated children's literature segment has been evolving in the Greek book market, while also exploring factors that play a central role in its selection and transfer. In this effort, we utilize the limited quantitative data we have been able to locate while also developing a qualitative analysis of five interviews, conducted with three translators and two executives from prominent publishing houses in Greece. The interviewees were: Kostia Kontoleon (translator), Ilias Mandilaras (translator), Argiro Pipini (translator), Vaso Papageorgiou (executive from Metechmio publications), and Thanos Psichogios (executive from Psichogios publications).

\section{Quantitative data about the current state of translations for children and youth in}

\section{Greece}

In 2012, the National Book Center of Greece published The Book Market in Greece report, providing statistics about translations for all ages, including children, teens, and adults. According to the report, foreign books in translation take up a significant share of the market. Comparing statistics from 2006 to 2011 (Figure 1), the center identified a decline in this share (from about $40 \%$ to $30 \%$ ) viewing this as a result of the economic crisis ("The Book Market in Greece" 6). 
Figure 1 - Yearly Publication of New Translations Compared to Total Yearly Book Production

\begin{tabular}{llllll}
\hline $\mathbf{2 0 0 6}$ & $\mathbf{2 0 0 7}$ & $\mathbf{2 0 0 8}$ & $\mathbf{2 0 0 9}$ & $\mathbf{2 0 1 0}$ & $\mathbf{2 0 1 1}$ \\
\hline $42.5 \%$ & $40.3 \%$ & $41.6 \%$ & $38.8 \%$ & $34.2 \%$ & $32.1 \%$ \\
\hline
\end{tabular}

Because the National Book Center of Greece was shut down in 2013 by the Greek government - in accordance to national and European financial austerity measures — we have no access to more recent official statistics.

Reflecting on the state of the Greek book industry in 2016, a year after the third bailout deal between Greece and the European Union, literary agent Evangelia Avloniti cites similar figures with the 2012 National Book Center Report, estimating the yearly publication of new translated titles to around $30 \%$ of the total book production. She also agrees that the financial recession played a central role in reducing the number of translations that are currently being imported to Greece. She explains that, "We've seen a significant rise in Greek-originated fiction titles in Greece during the last six years, which has been caused by a marked decrease in foreign fiction titles due to the high advance/translation costs" (Trentacosti). From one aspect, then, the 168 effects of globalization on Greek children's literature are in fact being contained by the effects of the financial crisis.

Writing about the effects of globalization on Italian children's publishing, Manuela Salvi writes that Italy has seen some decrease in imported new titles as well but bookstore shelves are still overflowing with imported children's literature; this does not seem to be the case in Greece. Nevertheless, Socrates Kabouropolos observes that "There is clearly a strong demand for foreign fiction, the figures showing a stability despite the general fall of the number of titles after 2009” (“The Greek Publishing Market During the Economic Crisis” 6). Readers' attitudes towards translations in Greece feature as quite positive, when one looks at the presence of foreign titles (50\%) in a 2012 list of best-selling books for adults, cited in the Center's report.

In 2011, around 53\% of translations published in Greece were from English, with French coming far behind in second place ("The Book Market in Greece" 6). Similar figures have been reported for 2016 :

English language dominates in the number of translations (50\%), followed by French (11-12\%), German (4\%), Spanish (4\%), Italian (3\%), Russian (1\%), and 33 other languages (all Scandinavian \& Balkan languages, Portuguese, Arabic, Polish, Hungarian, Czech, Dutch, Catalan, Japanese, Chinese, etc.) ("The Greek Publishing Market During the Economic Crisis") 
The most recent available statistics regarding contemporary translations explicitly addressed to children and young adults in Greece come from the journal Ichneftis, which reported that in 1995 translated children's literature was outnumbering original Greek texts for children and youth: out of the 680 titles published in 1995, 422 titles were translations. Noticeably, 66\% of all translations were from English to Greek, 200 coming from the UK and 78 from the US. Imports from France (53), Germany (38), Italy (17), Belgium (9), Japan (8) and Spain (7) followed (Voukelatos 22). When it comes to the sources of international children's books, the statistics are quite similar to those cited above about the sources of translations for all age groups. Historically, it seems that trends in translation sources in Greece apply in comparable ways to literature for children and literature for adults.

\section{Interview findings}

In the five interviews we conducted, we explored these trends and other relevant issues, aiming to get a more complete picture of translated children's literature in Greece, particularly the selection processes and factors that play into it. The first question answered by interviewees had to do with the geographical/ cultural/ linguistic areas from which texts for children and young adults are traveling from to get to Greece.

\section{What are the geographical/ cultural/ linguistic regions from which texts are imported?}

All interviewees agreed that the vast majority of children's texts that are imported to Greece come from English-speaking countries (mainly from the UK and the US). They tended to estimate that the British and American book markets are equally represented in Greek translations, even though some of the statistics cited earlier in this paper present the UK as a more dominant source.

Interviewees did not agree about the share of the rest of the languages/literatures in the Greek translation market. They identified French, Spanish, Italian, and German as having a significantly smaller but noticeable share. Additionally, the following were other countries they named as sporadic exporters of children's literature to Greece: Sweden and other Nordic countries (which are interestingly grouped as one by most interviewees), Holland, Portugal, India, and China. As explained by interviewees, translation from these countries depends heavily on translation stipends and the international recognizability of individual authors.

In a different study, we compared the covers of 68 Greek translations to the covers of their source texts (Panaou and Tsilimeni). These were children's and young adult books that 
had been translated and imported to Greece by two major Greek children's literature publishers, Patakis and Psychogios, over the past ten years. The translated covers we analyzed in that paper concur with our interview findings in terms of English being the dominant source language; they overwhelmingly came from the US and the UK. This is indicative but not definitive, as our booklist was not comprehensive; the book covers we examined represented a sample of convenience that to some extend represented the phenomenon under study (Merriam). We should also note that in our comparative study of translated covers the American source texts outnumbered the British, which contradicts both what our interviewees said (equal share) and what statistics show (more from the UK). An additional small number of titles in the covers study came from Australia, Italy, Spain, Sweden, Finland, and Germany.

Regardless of whether UK or US imports are in the majority, all studies and statistics indicate that the vast majority of imported texts are translated from English. Our interviewees provided the following reasons behind the dominance of English-source translations:

1. The universality of English.

2. Books being imported from places, cultures, and languages that are familiar to Greek publishers.

3. Financial issues, meaning that the lesser known a language is the more translation costs there will be.

4. The voluminous production of children's books in the UK and the US.

5. Cultural relevance, especially when it comes to a text's relevance to global mass culture. Illustrating this aspect, one of the interviewees stated that, because of globalized mass culture, "Disney-raised" kids are expected to comprehend and relate better to American stories.

6. Aggressive marketing campaigns of multinational publishers with ever-growing influence on Greek and international media and collaborations with the American film industry.

Publishing executive Thanos Psychogios purported that the main selection criterion is not the source country/ language but the book's quality, content, writing style, and appeal to the readers. It seems, however, that important factors narrow down the selection field before all of these criteria even begin to be applied. 


\section{What are the processes followed by Greek publishers to reach decisions about publishing translations?}

Interviewees stated that there are no universal or standard selection and decision-making processes followed by all Greek publishers. They did concur though that these processes usually include at least two stages: (1) search and identification of texts for potential translation; and (2) evaluation of identified texts. The search for international texts is dependent on each publisher's access to book catalogs, book exhibitions, the international press, and colleagues in other countries. Greek publishers might also enlist the professional help of literary agents and scouts. One of the translators observed that the later are usually British or American, implying that they mainly promote texts from their own countries. In big publishing houses, the evaluation process is usually undertaken by a team, with the languages spoken by this team playing an important role in the process, and the final decisions are usually taken by a board.

\section{Which factors/ criteria carry the most weight in a Greek publisher's decision to publish a translation?}

Of particular interest are the different elements Greek publishers consider during their search and evaluation processes. The interviewees identified thirteen different criteria that inform Greek publisher's decision to publish a translation, rating the first three as the most important:

1. The author's name and recognizability, in terms of the author being widely known, having received praising reviews in the international press, having a broad international and/or Greek fun-base, and having connections in the film industry with books by this author being turned into movies.

2. National and international awards received by the author and/or the book.

3. Positive reception and commercial success of the book in other countries. Indicatively, translator Kostia Kontoleon stressed that in the past, there have been "Homeric battles" between Greek publishers vying to secure the copyrights for international best-sellers.

4. Greek book market needs, such as current trends, audience preferences, or limited local production.

5. To fill in "empty slots" in the publisher's portfolio.

6. Literary quality. 
7. Content and theme compatibility with Greek social and cultural values and environment.

8. Absence of linguistic and ethical taboos that may put off parents and teachers.

9. Cost of translation copyrights.

10. Available funding for translations from the specific language.

11. Engaging plot.

12. Originality.

13. Appropriateness for youth audiences, as perceived by the publisher.

The first three factors listed above seem to carry the most weight. Our findings in the comparative study of translated covers mentioned earlier reinforce this idea. Greek publishers seem to think that readers/ buyers of translated texts in Greece will select a translation mainly because of its commercial success in other countries, the accolades it has gathered, and the author's recognizability, internationally and in Greece. In agreement with these top criteria, when the author/ illustrator was internationally acclaimed, their name is printed in bigger and/or bolder fonts and placed centrally on the translated book cover. At the same time, big advertisement-like statements are printed on the cover, highlighting the received awards and international success (Panaou and Tsilimeni).

The translator Argiro Pipini reported a recent practice that challenges the effects of these factors, namely publishers securing the translation rights for a book directly with the foreign agent or publisher even before the book is out in its original language. This approach may be related to financial reasons, namely that copyright costs might be lower at this stage. On the other hand, it might still be that the Greek publisher trusts the recognizability and commercial success of an author even before they read their new book.

Kontoleon described some exceptions to the rule, where publishers risk to publish books that are unlikely to have commercial success, simply because they believe they have come across a masterpiece that negotiates important issues and ideas. Publishing executive Vaso Papageorgiou attributed more importance to the work's potential to transcend the boundaries of time and space, through its central (perhaps universal) ideas. While it is important to examine a work's potential to speak to diverse local audiences, an overt emphasis on books that feature "universal ideas" could hinder true intercultural communication and exchange through literature. 


\section{Which broad categories and genres of children's and YA literature are traditionally being translated into Greek?}

Yet another interview question had to do with the genres that are being translated. All interviewees agreed that, with some exceptions, the translated texts are almost exclusively prose. They provided the following reasons for this phenomenon:

1. The reading public's preferences.

2. The fact that publishers consider poetry un-profitable and difficult to translate.

3. The Greek market follows established international trends.

Most interviewees agreed that novels rank first in terms of the number of books translated and three out of five said that Young Adult (YA) novels are the ones that get most translated. Kontoleon commented that this fact deconstructs the myth that teenagers don't read. Picturebooks, fairytales, other "classic" stories, bedtime stories, and non-fiction follow. Interviewees did not seem to agree about the order in which these other genres follow, though. Pipini claimed that a big portion of translated books for young and older children are nonfiction, while Kontoleon estimated that picturebooks come second after YA novels, and that classic fairytales come third. She purported that classic fairytale collections (in their original or abridged form) are a constant part of published translations in Greece, as they are considered to be steadily profitable.

Translator Ilias Mandilaras cautioned against the unchecked following of international publishing "fashion trends." On the other hand, he recognized that translation is often brought in to close existing gaps in the local production of texts for children and teens:

\footnotetext{
I would say that the translation of higher numbers of certain texts has to do with the market's needs for such texts. And because during the past ten years Greek authors produce huge amounts of short-length stories, only few such texts are translated in Greek. On the other hand, because the production of novels for older children and teens has been reduced (which means that quality texts under this category have also been reduced) we observe a more intense translation activity in this field during the past few years.
}

\section{What are the current trends in the transfer of texts from other cultures/languages to Greek children's and $\mathrm{YA}$ literature?}

Regarding current trends in the translation and transfer of texts, publishing executive Psychogios identified at least two genres that have been recently imported with huge success: 
graphic novels in the style of Diaries of a Wimpy Kid [Imerologio enos Spasikla] and romantic fantasy in the style of the Twilight Saga [Likofos]. He also identified an important influence of these imported genres on the work of Greek authors and illustrators.

Mandilaras observed that during the current era of financial turmoil, big publishers in Greece invest on "safe products"; books that are connected to a film adaptation or other wellknown products and characters. The majority of these come from the U.S. He explained, however, that a small number of publishers who wish to diversify and address a more qualitative section of the market choose smaller, mainly European, editions which are considered "difficult" to sell but more artistic.

Interviewees identified some problematic aspects in relation to prevalent themes. Kontoleon spoke about a timing discrepancy. Issues like youth substance abuse and violence, for instance, were foreign to the Greek social context when they first appeared in western Young Adult realistic fiction (problem novels). Now that these issues are very much present in Greece, the international trends in young adult literature have shifted. Even though interviewees seemed to agree on this asynchronous relevance of themes, there was confusion in their statements

174 about how the Greek translation market responds to them. Some claimed that, because of this timing, there has been an increase in translations of problem novels, others identified a constant publication of such translations, and yet others saw a decrease in the translation of problem novels and an increase of fantasy and science fiction translations. Papageorgiou seemed to think that issues of particular concern to Greek teenagers are effectively addressed by Greek translations, through a translation of diverse genres (from science fiction to mystery, and realistic or coming-of-age stories). Pipini, on the other hand, observed that some taboo themes, such as adoption or loss, which are widely addressed by foreign literatures, are still not favored by Greek publishers.

\section{What is the influence of translated texts on the Greek production of literature for children and young people?}

Interviewees referred to some major influences of translated texts on the Greek production of literature for children and young people. It is indicative that realistic fiction dealing with such "hot issues" such as racism and bullying first appeared in translation before they found their way into the work of Greek authors. Several interviewees cited the impact of the Harry Potter phenomenon and the rekindled popularity of Tolkien as significant forces in the development of fantasy in Greece. They also identified noticeable influences from the 
popularity of vampire and dystopian novels. Mandilaras explained that, while not many Greek authors write pure fantasy or dystopian fiction, many of them now include elements from these genres in their stories. Furthermore, Papageorgiou pointed to important international influences on Greek marketing practices, such as the production and promotion of book series rather than individual works. She explained that publishers discovered that this practice is quite effective in reinforcing the recognizability of both titles and authors.

\section{How should we expect the transfer of texts from other countries to Greece to evolve during the following years?}

Talking about future developments, Mandilaras estimated that the dominant tendency to judge international texts based on their commercial potential will continue. This means that publishers will continue to place value on attributes such as a book being an international bestseller, or being connected to a movie or to other products. He purported, however, that if Greek authors increase and improve their production of fiction for older children and young adults, this will mean that fewer texts will be imported, and that the ones that do get translated will be chosen based on more qualitative criteria. He envisioned this happening in parallel to the "easyselling" production of commercial hits, which will never go away.

All interviewees recognized the fact that the continuing crisis faced by the Greek economy is having its toll on the publishing industry. Psychogios stressed than no longer do publishers have the luxury of filling up bookstore shelves with new translations. They are much more selective and careful in their choices, considering both qualitative and commercial criteria. Some more literary and not quite commercial texts may end up not being translated, he said, but he also anticipated that, as long as the public preserves its cultural sensitivities, the translation of at least some small numbers of not as commercial titles will continue.

Kontoleon spoke about the future of children's literature translation in Greece in a similar vein:

This is a hard question to answer. A lot will depend on the financial state of the country. Nurturing the soul and mind comes second when the immediate need is survival, and what follows is a domino effect with detrimental consequences for the mental and cultural development of young people in this country. But let us hope, and let us wait for the best to come, because the country that gave birth to modern civilization cannot live without culture.

The ideas listed above add yet a third layer to the boundaries international books need to cross in order to reach children and youth in Greece; in addition to boundaries set by time 
and space, international texts also need to surmount formidable financial barriers that are set in their way.

\section{Final Remarks}

In spite of the challenges it faces, translated children's literature is expected to continue to have an important place in Greece. Looking at how the translated children's literature segment has been evolving in the Greek book market, we have explored factors that play a central role in its selection and transfer from other countries to Greece. We have utilized published quantitative data and also presented a qualitative analysis of five interviews, conducted with three Greek translators and two executives from prominent publishing houses in Greece. Based on both the quantitative and qualitative data analyzed in this paper, we expect translated literature for children and youth to continue to comprise about one third of new publications per year, with the majority of the texts coming from the U.S. and the U.K., and with factors like recognizability, national and international awards received, and commercial success in other countries continuing to play a decisive role in the selection process.

\section{BIBLIOGRAPHY}

Anagnostopoulos, Vassilis. "Xeni Paidiki Logotechnia Metafrasmeni stin Elliniki Glossa kata to Telos tou 18ou Aiona kai Arches tou 19ou Aiona." Diadromes, vol. 22, 1991, pp. 90-96.

Anagnostopoulos, Vassilis. Taseis kai Exelixeis tis Paidikis Logotechnias. Oi Ekdoseis ton Filon, 1996.

Kabouropoulos, Socrates, et al. The Book Market in Greece. National Book Center of Greece, 2012.

Kabouropoulos, Socrates. "The Greek Publishing Market During the Economic Crisis: Resilience, Innovation \& Change.” The 68th Frankfurt Book Fair, 2016, Frankfurt, Presentation.

Katsiki-givalou, Anta. "Society, History, and the Environment: Contemporary Concerns in Greek Children's Literature." Bookbird: A Journal of International Children's Literature, vol. 40, no. 1, 2002, pp. 47-51.

Merriam, Sharan. Qualitative Research and Case Study Applications in Education. JosseyBass, 1998.

Ntelopoulos, Kyriakos. Ta paidika anagnosmata ton pappon mas. Patakis, 2008.

Ntenisi, Sofia. Metafraseis mythistorimaton kai diigimaton 1830-1880: Isagogiki meleti kai katagrafi. Periplous, 1995. 
O’Sullivan, Emer. Comparative Children's Literature. Routledge, 2005.

Panaou, Petros. "Come Explore with me the Literary Treasures of Cyprus and Greece: A Short Introduction to Greek and Greek-Cypriot Children's Literatures." Bookbird: A Journal of International Children's Literature, vol. 56, no. 2, 2018, pp. 4-8.

Panaou, Petros, and Tasoula Tsilimeni. "Translated Book Covers as Peritextual Thresholds: Comparing Covers of Greek Translations to Covers of Source Texts." The Translation and Transmediation of Children's Literature, edited by Bjorn Sundmark and Anna Kerchy.

Manuscript submitted for publication, 2019.

Politis, Dimitrios. "Between Modernism and Postmodernism: Greek Literature for Children and Youth in the Last Decades of the Twentieth Century." Bookbird: A Journal of International Children's Literature, vol. 56, no. 2, 2018, pp. 52-56.

Salvi, Manuela. "Globalization and Italian Children's Publishing." Bookbird: A Journal of International Children's Literature, vol. 57, no. 1, 2019, pp. 53-57.

Trentacosti, Giulia. Publishing in Times of Crisis: Today's Greek Book Market. Sept. 2016, http://2seasagency.com/current-greek-publishing-market/. Accessed 19 Jun. 2019.

Voukelatos, Kostas. "Vivlia kai statistikes: I Elliniki Vivlioparagogi.” Ichneftis, vol. 16, 1995, pp. 22-25.

\footnotetext{
* Petros PANAOU - Clinical Associate Professor at the Department of Language and Literacy Education, University of Georgia, USA. PhD (2007) and MA (2001) in English Studies - Children's Literature at Illinois State University, USA. BSc in Education (1998) at the University of Cyprus, Republic of Cyprus. Athens, Georgia, The United States of America.

Academic Curriculum: https://coe.uga.edu/directory/people/ppanaou

ORCID: https://orcid.org/0000-0001-9265-9942

E-mail: ppanaou@uga.edu

** Tasoula TSILIMENI - Assistant Professor of Children's Literature, University of Thessaly, Greece. Volos, Greece.

Academic Curriculum: http://www.ece.uth.gr/main/content/639-tsilimeni-tasoula

ORCID: https://orcid.org/0000-0003-0707-9818

E-mail: tsilimeni@gmail.com
} 